\title{
Mediation of Distributive Justice on Dyadic Relationship between Leaders and Followers with Personal Outcomes
}

\author{
Yusniati Ishak*, Azman Ismail ${ }^{* *}$, Anis Anisah Abdullah***, \\ Asyakireen Samsudin****, Kartina Rahayu Mohamed***** \\ Received: April 30, 2018. Revised: September 17, 2018. Accepted: October 05, 2018
}

\section{Abstract}

Purpose - This study examined the relationship between dyadic relationship between leaders and followers (DRLF), distributive justice (DISJ), job satisfaction (JSTC), and organizational commitment (OGCM).

Research design, data, and methodology - 200 sets of survey questionnaires were distributed to the employees at a municipal office in East Malaysia using purposive sampling technique. Only 60 percent or 115 questionnaires were returned to the researchers. The survey data were analysed using the SmartPLS due to its ability to deliver latent construct scores, handle small sample size problems and estimate relationship between many constructs in the hypothesized model.

Results - The findings indicated that there is a significant correlated direct relationship between DRLF and DISJ and mediating relationship between DRLF, DISJ and personal outcomes, which are JSTC and OGCM.

Conclusions - This study confirms that DISJ does act as an important mediating variable in the relationship between DRLF with JSTC and DRLF with OGCM. Other dimensions of personal outcomes, such as extra-role behaviour, job motivation and service quality should be considered in future study because they are found to be the important outcomes of the relationship between DRLF and DISJ. The importance of these issues need to be further advanced in future research.

Keywords: Dyadic relationship between leaders and followers, distributive justice, job satisfaction, organizational commitment, SmartPLS.

JEL Classifications: L00, L20.

\section{Introduction}

In an era of competitive and demanding environments, dyadic relationship between leaders and followers (DRLF) is crucial in enhancing organizational effectiveness (Yang \& Ju,

* First Author, Master degree candidate, Graduate School of Business, Universiti Kebangsaan Malaysia, 43600 UKM, Selangor, Malaysia. Email: yuss294@gmail.com

** Co-author, Associate Professor, Faculty of Economics \& Management, Universiti Kebangsaan Malaysia, 43600 UKM, Selangor, Malaysia. Email: azisma12@ukm.edu.my

*** Co-authors, Master degree candidate, Institut Islam Hadhari, Universiti Kebangsaan Malaysia, 43600 UKM, Selangor, Malaysia. E-mail: anisanisahabdullah93@gmail.com

**** Corresponding Author, PhD candidate, Faculty of Economics \& Management, Universiti Kebangsaan Malaysia, 43600 UKM, Selangor, Malaysia. Email: syakanda1304@gmail.com

$\star \star \star \star *$ Co-author, Research assistant, Faculty of Economics \& Management, Universiti Kebangsaan Malaysia, 43600 UKM, Selangor, Malaysia.
2011). It refers to formal and/or informal relationship between managers and subordinates that occur in units/departments to achieve organizations'strategies and objectives. A review of the recent literature highlights that a high quality relationship between managers and subordinates may have a significant impact on workplace justice especially distributive justice (DISJ) (Sindhu et al., 2017) which enhance the personal outcomes. These personal outcomes mentioned are job satisfaction (JSTC) (Zafar et al., 2017) and organizational commitment (OGCM) (Maslyn et al., 2017).

Even though the studies have prominent significance towards personal outcomes, little is discussed about the mediating effect of DISJ in the workplace leadership research literature. Thus, this situation inspires the researchers to fill in the gap of literature by quantifying the mediating effect of DISJ in the relationship between DRLF and personal outcomes. 


\section{Literature Review}

Previous studies about workplace leadership had not produced sufficient findings to explain the whole meanings of DRLF and DISJ, as well as relationship between such variables. For example, a survey of 279 business-to-business salespeople in USA by Schwepker (2016) had only focused on the relationship between one element of DRLF, namely participation in quota setting and one element of DISJ, namely fairness in reward allocation. Even thoughthis study produced significant results, it did not sufficient to explain the effect of DRLF on DISJ in the organizations. Meanwhile, a survey of 306 professionals from 30 software organizations operating in different parts of India by Bhal (2006) had only emphasized on the relationship between one feature of DRLF, namely affective based relationship between leaders and followers, and DISJ. Outcomes of this study had not supported the relationship between variables in the organizations.

Recent studies about workplace leadership have used single constructs of DRLF and DISJ, as well asprovided strong theoretical and empirical findings to support the relationship between such constructs. The role of DRLF as an important predictor of personal outcomes has gained strong support from the notion of organizational behaviour theory. For example, Blau's (1964) social exchange theory emphasizes that interpersonal transaction between managers and subordinates is usually occur beyond economic gain, and this situation may strongly invoke followers' perceptions of DISJ in organizations. Further, Graen's (1976) role making theory posits that leaders usually interact with followers based on loyalty, respect and trust in performing daily jobs may strongly invoke followers' perceptions of DISJ in organizations. Application of these theories in workplace leadership shows that quality relationship between leaders and followers may act asan important determinant of personal outcomes(Sindhu et al., 2017; Yusniati et al., 2016).

Empirical studies supported the effect of DRLF on DISJ were summarized in $\langle$ Table 1$\rangle$.

<Table 1> Research Findings Supported the Relationship between DRLF and DISJ

\begin{tabular}{|c|c|c|c|}
\hline No & Year & Authors & \multicolumn{1}{c|}{ Unit of analysis } \\
\hline 1 & 1993 & Tansky & $\begin{array}{l}75 \text { non-union employees of Fortune } \\
100 \text { company }\end{array}$ \\
\hline 2 & 2005 & $\begin{array}{c}\text { Hassan and } \\
\text { Chandaran }\end{array}$ & 154 multi-level managers in Malaysia \\
\hline 3 & 2011 & Karim & $\begin{array}{l}106 \text { employees of six public sector } \\
\text { organizations situated in Quetta, Pakistan }\end{array}$ \\
\hline 4 & 2015 & Prahast et al. & 100 production employees in Malang \\
\hline 5 & 2016 & Yusniati et al. & $\begin{array}{l}120 \text { employees in one municipal office } \\
\text { in East Malaysia }\end{array}$ \\
\hline 6 & 2017 & Sindhu et al. & $\begin{array}{l}185 \text { managers at banking, sales \& } \\
\text { distribution, telecommunication, } \\
\text { transport, textile and engineering } \\
\text { organizations in Pakistan }\end{array}$ \\
\hline
\end{tabular}

The findings of these surveys showed that the managers arehighly concerned about mutual trust, respect and obligation in relationship with their subordinates. The willingness of managers to practice such quality relationships in performing day-to-day job operations had strongly invoked subordinates'perceptions of distributive justice in the respective organizations. Thus, it was hypothesized that:

$<\mathrm{H} 1>$ There is a positive relationship between DRLF and DISJ.

Further, extant studies revealed that the mediating effect of DISJ in the hypothesized model has received strong support from the notion of distributive fairness theory. For example, Adams (1963) equity theory mentions that fair treatment in exchanging and distributing inputs (e.g., effort, loyalty and sacrifice) and outputs (e.g., return) may positively affect individuals' actions. Thibaut and Walker's (1975) control theory state that employees who perceived justice on the outcomes they received may lead to induce favourable behaviour. Application of these fairnesstheories in a workplace leadership model shows that DISJ is an important link in between DRLF and personal outcomes. This notion has received strong support from DRLF research literature.

Several further studies were done using indirect effect model to assess distributive justice towards personal outcomes based on different organizational settings. The supported outcomes of these studies displayed that the ability of managers to practice high quality relationship with their subordinates in executing day-to-day job operations had invoked subordinates'perceptions of distributive justice. $<$ Table 2> summarized the findings as follows:

<Table 2> Research Findings Supported the Mediating Effect of DISJ in the Relationship between DRLF and Personal Outcomes.

\begin{tabular}{|c|c|c|l|c|}
\hline No & Year & Authors & \multicolumn{1}{|c|}{ Unit of analysis } & $\begin{array}{c}\text { Personal } \\
\text { outcomes }\end{array}$ \\
\hline 1 & 2000 & Lee & $\begin{array}{l}250 \text { employees served at } \\
\text { two Southern Virginia hotels }\end{array}$ & $\begin{array}{c}\text { JSTC and } \\
\text { OGCM }\end{array}$ \\
\hline 2 & 2005 & $\begin{array}{c}\text { Hassan and } \\
\text { Chandaran }\end{array}$ & $\begin{array}{l}154 \text { employees at four } \\
\text { Malaysian companies }\end{array}$ & $\begin{array}{c}\text { JSTC and } \\
\text { OGCM }\end{array}$ \\
\hline 3 & 2007 & $\begin{array}{c}\text { Bhal and } \\
\text { Ansari }\end{array}$ & 295 IT professionals in India & JSTC \\
\hline 5 & 2016 & $\begin{array}{c}\text { Gichira et al. } \\
\text { I95 employees at Health } \\
\text { Sector Non-Governmental } \\
\text { Organizations in Kenya }\end{array}$ & OGCM \\
\hline
\end{tabular}

The literatures have been used as a foundation to establish a conceptual framework as exhibited in <Figure 1>. 


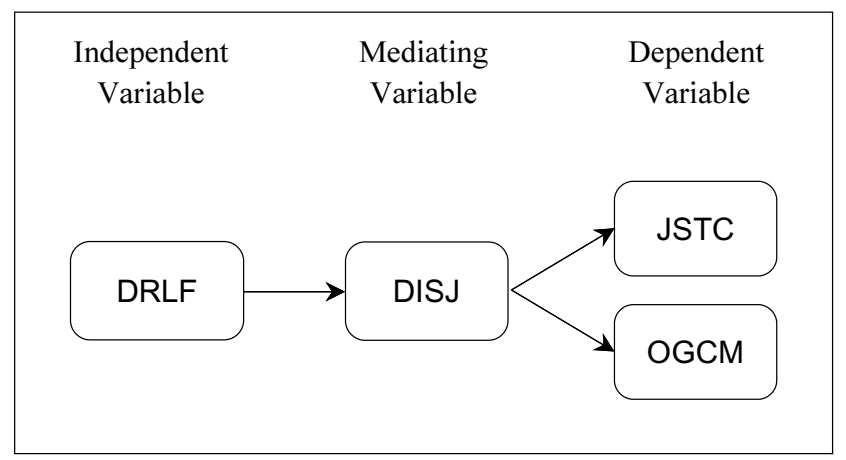

<Figure 1> Conceptual Framework

Based on the framework, the following hypotheses are established:

$<\mathrm{H} 2>$ DISJ mediates the relationship between DRLF and JSTC

$<$ H3> DISJ mediates the relationship between DRLF and OGCM

\section{Research Method}

This study applies quantitative methodology through leadership research literatures, in-depth interview and actual survey as the procedure of data collection. According to Creswell (2014) and Sekaran and Bougie (2015), application of this procedure may collect accurate, less bias dataand high quality data (Azman et al., 2009).

This study was conducted at a municipal office in East Malaysia. At the first step of data collection, survey questionnaire was drafted based on the DRLF literature. After that, a back translation technique was used to translate the survey questionnaire into English and Malay languages in order to increase the validity and reliability of research results (Sekaran \& Bougie, 2015; Creswell, 2014; Peng, 2013).

\subsection{Measures}

The survey questionnaire was divided into four sections shown in <Table $3>$ as follows:

< Table 3> Number of Items According to Constructs

\begin{tabular}{|c|c|c|c|}
\hline No. & Constructs & Adaptation from & $\begin{array}{c}\text { Number of } \\
\text { items }\end{array}$ \\
\hline 1 & DRLF & Dionne (2000) & 6 \\
\hline 2 & DISJ & Colquitt (2001) and Lee (2000) & 6 \\
\hline 3 & JSTC & Murray (1999) & 4 \\
\hline 4 & OGCM & Guchait (2007) & 6 \\
\hline
\end{tabular}

All items are to be rated based on 7-itemsscale ranging from "strongly disagree/dissatisfied" (1) to "strongly agree/ satisfied" (7). The demographic variables were used as controlling variables because this study focused on measuring employees' attitudes.

\subsection{Sample}

The unit of analysis for this study is employees at the organization. The name of this organizationremains anonymous for some confidentiality reasons. Purposive sampling plan was used to distribute 200 survey questionnaires to employees in the organizations. This sampling plan was chosen because the organization head had not provided a list of registered employees to the researchers and this conditiondid not allow the researchers to select participants using a random technique. From the number, 115 (60 percent) usable survey questionnaires were returned to the researchers. The participants answered the survey questionnaires based on their consents and a voluntarily basis.

The SmartPLS was utilized to analyse the instrument of this study because it could deliver latent construct scores, handle small sample size problems and estimate relationship between many constructs in the hypothesized model (Hair et al., 2017). The procedures of data analysis included few analysis processes and steps. First, the validity and reliability of instrument were determined using a confirmatory factor analysis. Second, the structural model was inspected based on the path coefficients for example standardized betas $(\beta)$ and $t$ statistics. For a direct effects model, $t$ statistics is greater than 1.65 (one tail testing) for the relationship between variables will show a significant hypothesis. Conversely, for a mediating model, $t$ statistics is greaterthan 1.96 (two tail testing) for the relationship between variables will show a significant hypothesis. Third, the value of R2is used as a criterion for determining the overall predictive strength of the model based on the rules: 0.02 (weak effect), 0.26 (substantial effect) and 0.13 (moderate effect) (Cohen, 1988). Fourth, the value of f2was used as a measure to determine the effect size of predicting variable in the model based on the criteria: 0.02 (weak), 0.15 (medium) and 0.35 (large) (Hair et al., 2017). Finally, the value of Q2for dependent variable higher than zero will show that the model has predictive relevance (Hair et al., 2017).

\section{Results}

<Table 4> shows that most respondents were aged between 20 and 29 years old (44.3\%) females (54.8\%), with 5 years and above working experience (45.2\%) and medium secondary school (SPM/MCE) holders (43.5\%). 
$<$ Table 4> Respondents Profile $(n=115)$

\begin{tabular}{|c|c|c|c|c|}
\hline No. & $\begin{array}{c}\text { Respondents } \\
\text { Profile }\end{array}$ & Sub Profile & Frequency & Percentage \\
\hline 1. & Age & $\begin{array}{l}\text { Less than } 20 \text { years old } \\
20-29 \text { years old } \\
30-39 \text { years old } \\
40-49 \text { years old } \\
50-59 \text { years old }\end{array}$ & $\begin{array}{c}5 \\
51 \\
17 \\
29 \\
13\end{array}$ & $\begin{array}{c}4.3 \\
44.3 \\
14.8 \\
25.2 \\
11.3 \\
\end{array}$ \\
\hline & Gender & $\begin{array}{c}\text { Male } \\
\text { Female } \\
\end{array}$ & $\begin{array}{l}52 \\
63 \\
\end{array}$ & $\begin{array}{l}45.2 \\
54.8 \\
\end{array}$ \\
\hline & $\begin{array}{l}\text { Length of } \\
\text { service }\end{array}$ & \begin{tabular}{|c|} 
Less than 1 year \\
$1-2$ year \\
$3-4$ year \\
5 year and above \\
\end{tabular} & $\begin{array}{l}31 \\
14 \\
18 \\
52 \\
\end{array}$ & $\begin{array}{l}27.0 \\
12.2 \\
15.7 \\
45.2 \\
\end{array}$ \\
\hline & $\begin{array}{l}\text { Level of } \\
\text { education }\end{array}$ & \begin{tabular}{|c|} 
LCE/ SRP/ PMR \\
MCE/ SPM \\
HCE/ STPM \\
Diploma \\
Bachelor/ Master's Degree \\
\end{tabular} & $\begin{array}{c}15 \\
50 \\
16 \\
26 \\
8 \\
\end{array}$ & $\begin{array}{c}13.0 \\
43.5 \\
13.9 \\
22.6 \\
7.0 \\
\end{array}$ \\
\hline
\end{tabular}

$<$ Table 5> depicts the results of convergent validity and reliability assessment. Factor loading for all items that represent DRLF were from 0.708 to 0.823 , DISJ were from 0.713 to 0.829 , JSTC were from 0.721 to 0.809 and OGCM were from 0.735 to 0.816 . Thus, all items that represent the research constructs had factor loadings greater than 0.70 (Fornell \& Larcker, 1981; Hair et al., 2017), indicating that they meet acceptable standard of convergent validity. Conversely, average variance extracted (AVE)11 AVEAverage Variance Extracted values for DRLF were 0.565 , DISJ was 0.611 , JSTC was 0.583 , and OGCM was 0.590 . These AVE values were above the threshold value of 0.50 (Fornell \& Larcker, 1981; Hair et al., 2017; Henseler et al., 2009) all constructs meet the acceptable standard of convergent validity analysis. While, the Cronbach's Alpha values and composite reliability for all constructs were above 0.80 (Hair et al., 2017; Nunnally \& Bernstein, 1994), indicating that the constructs had high internal consistency.

<Table 5> The Convergent Validity and Composite Reliability

\begin{tabular}{|c|c|c|c|c|c|}
\hline Constructs & $\begin{array}{c}\text { No. of } \\
\text { Items }\end{array}$ & $\begin{array}{c}\text { Factor } \\
\text { Loadings }\end{array}$ & AVE & $\begin{array}{c}\text { Cronbach } \\
\text { Alpha }\end{array}$ & $\begin{array}{c}\text { Composite } \\
\text { Reliability }\end{array}$ \\
\hline DRLF & 6 & $0.708-0.823$ & 0.565 & 0.846 & 0.886 \\
\hline DISJ & 6 & $0.713-0.829$ & 0.611 & 0.873 & 0.904 \\
\hline JSTC & 4 & $0.721-0.809$ & 0.583 & 0.822 & 0.875 \\
\hline OGCM & 6 & $0.735-0.816$ & 0.590 & 0.861 & 0.896 \\
\hline
\end{tabular}

$<$ Table 6> shows the results of discriminant validity. The values of AVE square root in diagonal for DRLF (0.752), DISJ (0.782), JSTC (0.763), and OGCM (0.768) were greater than the squared correlation with other constructs in off-diagonal, showing that these constructs fulfil the requirements of discriminant validity (Hair et al., 2017).
<Table 6> Discriminant Validity Assessment

\begin{tabular}{|l|c|c|c|c|}
\hline \multirow{2}{*}{ Constructs } & \multicolumn{4}{|c|}{ Fornell Lacker Criterion } \\
\cline { 2 - 5 } & $\mathbf{1}$ & $\mathbf{2}$ & $\mathbf{3}$ & $\mathbf{4}$ \\
\hline 1. DRLF & 0.752 & & & \\
\hline 2. DISJ & 0.630 & 0.782 & & \\
\hline 3. JSTC & 0.669 & 0.625 & 0.763 & \\
\hline 4. OGCM & 0.732 & 0.751 & 0.795 & 0.768 \\
\hline
\end{tabular}

$<$ Table 7> exhibits the outcomes of discriminant analysis for all constructs. The values of all indicators (items) for their own constructs are more than 0.70 , and loweron other constructs, indicating that all constructs meet the standards of discriminant analysis (Hair et al., 2017).

$<$ Table 7> Factor Loadings and Cross Loading for Different Constructs

\begin{tabular}{|c|c|c|c|c|}
\hline & DRLF & DISJ & JSTC & OGCM \\
\hline DRLF 1 & 0.741 & 0.397 & 0.545 & 0.584 \\
\hline DRLF 2 & 0.773 & 0.456 & 0.550 & 0.581 \\
\hline DRLF 3 & 0.754 & 0.442 & 0.554 & 0.569 \\
\hline DRLF 4 & 0.789 & 0.566 & 0.450 & 0.543 \\
\hline DRLF 5 & 0.739 & 0.442 & 0.432 & 0.545 \\
\hline DRLF 6 & 0.713 & 0.537 & 0.480 & 0.479 \\
\hline DISJ 1 & 0.367 & 0.743 & 0.402 & 0.579 \\
\hline DISJ 2 & 0.448 & 0.772 & 0.486 & 0.553 \\
\hline DISJ 3 & 0.430 & 0.802 & 0.412 & 0.539 \\
\hline DISJ 4 & 0.448 & 0.726 & 0.491 & 0.545 \\
\hline DISJ 5 & 0.608 & 0.814 & 0.599 & 0.657 \\
\hline DISJ 6 & 0.600 & 0.829 & 0.508 & 0.630 \\
\hline JSTC 1 & 0.463 & 0.434 & 0.799 & 0.582 \\
\hline JSTC 2 & 0.413 & 0.395 & 0.721 & 0.534 \\
\hline JSTC 3 & 0.602 & 0.487 & 0.809 & 0.677 \\
\hline JSTC 4 & 0.511 & 0.515 & 0.729 & 0.611 \\
\hline JSTC 5 & 0.534 & 0.531 & 0.756 & 0.612 \\
\hline OGCM 1 & 0.591 & 0.523 & 0.655 & 0.735 \\
\hline OGCM 2 & 0.552 & 0.541 & 0.596 & 0.735 \\
\hline OGCM 3 & 0.584 & 0.586 & 0.571 & 0.796 \\
\hline OGCM 4 & 0.643 & 0.667 & 0.685 & 0.816 \\
\hline OGCM 5 & 0.481 & 0.638 & 0.648 & 0.787 \\
\hline OGCM 6 & 0.513 & 0.484 & 0.495 & 0.735 \\
\hline
\end{tabular}

$<$ Table 8> presents the outcomes of descriptive statistics and variance inflation factor (VIF) VIF - Variance Inflation Factor for all constructs. The mean values for all constructs are from 5.4493 to 5.5797 indicating that the levels of DRLF, DISJ, JSTC and OGCM range from high (4) to the highest level (7). Conversely, the values of VIFfor all constructs are less than 5.00 , indicating that the constructs are free from the serious collinearity problems (Hair et al., 2017). 
<Table 8> Descriptive Statistics and Variance Inflation Factor

\begin{tabular}{|l|c|c|c|}
\hline \multicolumn{1}{|c|}{ Construct } & Mean & Standard Deviation & VIF \\
\hline 1. DRLF & 5.4493 & 0.128 & - \\
\hline 2. DISJ & 5.5043 & 0.094 & - \\
\hline 3. JSTC & 5.5165 & 0.084 & 1.657 \\
\hline 4. OGCM & 5.5797 & 0.068 & 1.657 \\
\hline
\end{tabular}

$<$ Table 9> denotes the outcomes of testing $\mathrm{H} 1$. The inclusion of DRLF in the analysis had explained 40 percent of variance in DISJ. In terms of explanatory power, this model has large effect. The outcomes of testing the hypothesis showed that DRLF was positively and significantly related to DISJ $(\beta=0.630, t=6.735)$, therefore $\mathrm{H} 1$ was supported. This result confirms that DRLF is an important determinant of DISJ.

$<$ Table 10> shows that the outcomes of testing the indirect effects model. The inclusion of DRLF and DISJ in the analysis had explained 30 percent of JSTC. While, the inclusion of DRLF and DISJ in the analysis had explained 68 percent of OGCM. In terms of explanatory power, this model has substantial effect. Further, the outcomes of testing the hypotheses showed two important findings: first, relationship between DRLF and DISJ was significantly related to JSTC $(\beta=0.212, \quad t=2.528)$, therefore $\mathrm{H} 2$ was supported. Also, the 95\% Bootstrap Confidence Interval (Cl) $\mathrm{Cl}$ - Confidence Intervaldoes not straddle a 0 in between [LLCl=0.069, UL=0.396], indicating that DISJ mediates the relationship between DRLF and JSTC (Preacher \& Hayes, 2008). Second, relationship between DRLF and DISJ was significantly related to OGCM ( $\beta=0.302, \mathrm{t}=4.445$ ), therefore H3 was supported. Also, the $95 \%$ Bootstrap Confidence Interval $(\mathrm{Cl})$ does not straddle a 0 in between [ $\mathrm{LLCl}=0.160$, $\mathrm{ULCl}=0.421]$, indicating that DISJ mediates the relationship between DRLF and OGCM (Preacher \& Hayes, 2008). In overall, the above results have supported the mediating effect of DISJ in the hypothesized model.

$<$ Table 11> exhibits the type of mediation analysis based on Hair et al. (2017) and Zhao et al. (2010) procedures. The results of this test showed that DISJ has partially mediated: a) the relationship between DRLF and JSTC; and b) the relationship between DRLF and OGCM.

\section{Discussion}

The findings of this study exposed that DISJ acts as an important mediating variable in the relationship between DRLF with JSTC and OGCM. In the context of this organization, management has high awareness to practice good relationship with subordinates as a mean to accomplish their organizations' strategy and objectives. The majority of respondents perceived that the levels of DRLF, DISP, JSTC, and OGCM are high. This situation explains that the ability of managementto appropriately practice high quality interaction with subordinates will strongly invoke subordinates'perceptions of DISJ. Consequently, this perception may lead to greater JSTC and OGCM in the organization.

$<$ Table 9> Outcomes of Testing the $\mathrm{H} 1$

\begin{tabular}{|c|c|c|c|c|c|c|c|}
\hline Relationships & $\beta$-value & $\mathbf{R}^{\mathbf{2}}$ & t-value & p-value & $\mathbf{5 \% ~ L L C l}$ & $\mathbf{9 5 \%}$ ULCl & $\mathbf{R}$ Square \\
\hline DRLF DISJ & 0.630 & 0.397 & 6.735 & 0.000 & 0.398 & 0.763 & 0.397 \\
\hline
\end{tabular}

Note: Significant at $\mathrm{t}>1.96 ; \mathrm{p}<0.05$ (one tail testing)

$\mathrm{LLCl}=$ Lower Level Confidence Interval, ULCl $=$ Lower Level Confidence Interval

$<$ Table 10> Outcomes of Testing H2 and H3

\begin{tabular}{|c|c|c|c|c|c|c|}
\hline Relationships & $\beta$-value & $\mathbf{R}^{2}$ & t-value & p-value & $\mathbf{5 \%} \mathbf{~ L L C l}$ & $\mathbf{9 5 \%}$ ULCl \\
\hline DRLF DISJ JSTC & $0.212^{*}$ & 0.517 & 2.528 & $\begin{array}{c}\text { Yes } \\
0.012\end{array}$ & 0.069 & 0.396 \\
\hline DRLF DISJ OGCM & $0.302^{* *}$ & 0.675 & 4.445 & $\begin{array}{c}\text { Yes } \\
0.000\end{array}$ & 0.160 & 0.421 \\
\hline
\end{tabular}

Note: $\mathrm{LLCl}=$ Lower Level Confidence Interval, ULCI = Upper Level Confidence Interval

$<$ Table 11> Type of Mediation Analysis Assessment

\begin{tabular}{|c|c|c|c|c|c|c|c|}
\hline \multirow[b]{2}{*}{ Relationships } & \multicolumn{3}{|c|}{ Direct Effect } & \multicolumn{3}{|c|}{ Indirect Effect } & \multirow[b]{2}{*}{$\begin{array}{l}\text { Types of } \\
\text { Mediation }\end{array}$} \\
\hline & $\beta$-value & t-value & $\begin{array}{c}\text { Significant } \\
\text { p-value }\end{array}$ & $\beta$-value & t-value & $\begin{array}{c}\text { Significant } \\
\text { p-value }\end{array}$ & \\
\hline DRLF DISJ JSTC & $0.457^{* *}$ & 5.236 & $\begin{array}{c}\text { Yes } \\
(p<0.000)\end{array}$ & $0.212^{*}$ & 2.528 & $\begin{array}{c}\text { Yes } \\
(p<0.012)\end{array}$ & Partial \\
\hline DRLF DISJ OGCM & $0.430^{* *}$ & 5.925 & $\begin{array}{c}\text { Yes } \\
(p<0.000)\end{array}$ & $0.302^{* *}$ & 4.445 & $\begin{array}{c}\text { Yes } \\
(p<0.000)\end{array}$ & Partial \\
\hline
\end{tabular}

Note: Significant at $\mathrm{t}>1.645, \mathrm{p}<0.05$ (two tail testing)

$\mathrm{LLCl}=$ Lower Level Confidence Interval, ULCl $=$ Lower Level Confidence Interval 
This study provides three major contributions: theoretical, robustness of research methodology and practical. According to theoretical contribution, the results of this study expose that DISJ has mediated the effect of DRLF on JSTC and OGCM. This finding is consistent with extended studies by Lee (2000), Hassan and Chandaran (2005), Bhal and Ansari (2007), Gichira et al. (2016) and Zafar et al. (2017). Concerning the robustness of research methodology, the survey questionnaire employed in this study has satisfied the acceptable standards of the validity and reliability analyses. This condition could lead to accurate and reliable research results.

From a practical contribution, the findings of this study may useas important guidelines by management to improve leadership behaviour in the organizations. In order to achieve this aim, management needs to focus on the following aspects: first, leadership training program curriculum should updated to upgrade managers' knowledge and skills in communicating, involving and engaging with diverse employee backgrounds and expectations. These abilities may assist managers to influence employees in achieving their job targets. Second, pay rises and levels to higher performing employees should revisited according to current organizational strategy and job challenges. If higher performing employees feel that they receive the type, level and/ amount of reward equal with their contributions, this may motivate them toimproved customer service and productivity. Third, participative work culture should be promoted in order to enhance cooperation and collaboration between management and employees in performing yearly key performance indicators. If the above suggestions are given more attention, this may encourage employees to support their organizations'strategic business mission and vision.

\section{Conclusions}

The results of this research confirm that DISJ acts as an important mediating variable in the relationship between DRLF and personal outcomes, which areJSTC and OGCM. This result also has supported and broadened the previous studies mostly done in Western countries.

This research acknowledges some limitations: first, data gathered from the cross-sectional research design have neglected the development issue and detail causal correlation between the variables of interest. Second, this study has not measured specific dimensions for DRLF, DISP, JSTC, and OGCM. Third, thisstudy is done at a municipal council office. Finally, purposivesampling plan cannot control response bias. These limitations may reduce the ability of generalizing the results of this study to other organizational settings.

This study provides few suggestions to strengthenfuture research: first, a longitudinal research design should be used in future study because it able to detect patterns of change and the direction and magnitude of causal relationships amongst variables of interest. Second, a larger sample size should be taken because it may represent the population. Third, more than one organizations should be used in future study because their results may show similarities and differences within different organizational settings. Fourth, other components of DRLF such as trust, honesty, and decision-making should be utilized in future research because they are widely recognized as important determinants of DISJ. Other elements of DISJ such as adequacy of outcome and award basis should be utilized in future study because they are widely acknowledged as important mediating variables in between DRLF and personal outcomes. Finally, other dimensions of personal outcomes, such as extra-role behaviour, job motivation and service quality should be considered in future study because they are found to be important outcomes of the relationship between DRLF and DISJ. The importance of these issues needs to be further advanced in future research.

\section{References}

Adams, J. S. (1963). Towards an understanding of inequity. Journal of Abnormal and Social Psychology, 67(5), 422-436.

Azman, I., Dayang, K. A. I., \& Girardi, A. (2009). The mediating effect of distributive justice in the relationship between pay design andjob satisfaction. Zbornik Radova Ekonomskog Fakulteta U Rijeci-Proceedings of Rijeka Faculty of Economics, 27(1), 129-147.

Bhal, K. T. (2006). LMX--citizenship behavior relationship: justice as a mediator. Leadership \& Organization Development Journal, 27(2), 106-117.

Bhal, K. T., \& Ansari, M. A. (2007). Leader-member exchange-subordinate outcomes relationship : role of voice and justice. Journal of Hospitality Marketing \& Management, 28(1), 20-35.

Blau, P. M. (1964). Justice in Social Exchange. Sociological Inquiry, 34(2), 193-206.

Cohen, J. (1988). Set Correlation and Contingency Tables. Applied Psychological Measurement, 12(4), 425 $-434$.

Creswell, J. W. (2014). Research design: qualitative, quantitative and mixed methods approaches ( $\left.4^{\text {th }} \mathrm{ed}\right)$. Thousand Oaks, CA: SAGE Publication.

Dionne, L. (2000). Leader-member exchange (LMX): Level of negotiating latitude and job satisfaction. Shippagan: University De Moncton.

Fornell, C., \& Larcker, D. F. (1981). Evaluating structural equation models with unobservable variables and measurement error. Journal of Marketing Research, 
XVIII, 39-50.

Gichira, P. M., Were, S. M., \& Orwa, G. O. (2016). Relationship Between Perceptions of Distributive Justice and Employee Commitment in Health Sector Non-Governmental in Kenya. European Journal of Human Resource, 1(1), 1-25.

Graen, G. (1976). Role making processes in complex organizations. In M. D. Dunnette, Handbook of industrial and organizational psychology (2nd ed). Chicago, IL: Rand Mc Nally.

Guchait, P. (2007). Human resource management practices and organizational support and psychological contracts. Columbia, MO: University of Missouri.

Hair Jr., J. F., Hult, G. T. M., Ringle, C. M., \& Sarstedt, M. (2017). A Primer on Partial Least Squares Structural Equation Modeling (PLS-SEM) (2nd ed.). Thousand Oaks, CA: SAGE Publication.

Hassan, A., \& Chandaran, S. (2005). Quality of supervisor-subordinate relationship and work outcome: Organizational justice as mediator. IIUM Journal of Economics and Management, 13(1), 1-20.

Henseler, J., Ringle, C. M., \& Sinkovics, R. R. (2009). The use of partial least squares path modeling in international marketing. Advances in International Marketing, 20, 277-319.

Karim, J. (2011). Emotional intelligence, leader-member exchange, organizational justice, and outcome variables: A conceptual model. International Journal of Leadership Studies, 6(3), 390-411.

Lee, H.-R. R. (2000). An Empirical Study of Organizational Justice as a Mediator of the Relationships among Leader-Member Exchange and Job Satisfaction, Organizational Commitment, and Turnover Intentions in the Lodging Industry.

Maslyn, J. M., Schyns, B., \& Farmer, S. M. (2017). Attachment style and leader-member exchange. Leadership \& Organization Development Journal, 38(3), $450-462$.

Murray, R. A. (1999). Job satisfaction of professional and paraprofessional library staff at the University of North Carolina, Chapel Hill. University of North Carolina, Chapel Hill.

Nunnally, J. C., \& Bernstein, I. H. (1994). Psychometric Theory ( $3^{\text {rd }}$ ed). New York, NY: McGraw-Hill.

Peng, H. C. (2013). Research Methodology Manual $\left(1^{\text {st }}\right.$ ed). Kuala Lumpur: National Institute of Public Administration (INTAN).

Prahast, D. K., Soetjipto, B. E., \& Hariri, A. (2015). The effect of leader-member exchange, procedural justice and distributive justice on organizational commitment through job satisfaction. International Journal of Applied Business and Economic Research, 13(7), 5523-5535.

Preacher, K. J., \& Hayes, A. F. (2008). Asymptotic and resampling strategies for assessing and comparing indirect effects in multiple mediator models. Behavior Research Methods, 40(3), 879-91.

Schwepker Jr, C. H. (2016). Servant leadership, distributive justice and commitment to customer value in the salesforce. Journal of Business \& Industrial Marketing, 31(1), 70-82.

Sekaran, U., \& Bougie, R. (2015). Research Methods for Business: $A$ Skill-Building Approach ( $6^{\text {th }}$ ed). New Delhi.

Sindhu, M. I., Ahmad, H. M., \& Hashmi, S. H. (2017). Leader-member exchange relationship and organizational justice: Moderating role of organizational change. International Journal of Organizational Leadership, 6, 276-282.

Tansky, J. W. (1993). Justice and organizational citizenship behavior: What is the relationship? Employee Responsibilities and Rights Journal, 6(3), 195 $-207$.

Thibaut, J., \& Walker, L. (1975). Procedural Justice: A Psychological Analysis. (Hillsdale, Ed.). N.J: Erlbaum.

Yang, H.-C., \& Ju, Y. (2011). Positive integration of the franchise system: A new perspective on leadership, followership, trust and group efficacy. East Asian Journal of Business Management, 1(1), 5-8.

Yusniati, I., Azman, I., \& Kartina, R. M. (2016). Relationship Between Leader-Member Exchange, Job Satisfaction and Organizational Commitment: The Mediating Effect of Social Science, 140-148.

Zafar, I. M., Rehan, M., Fatima, A., \& Nawab, S. (2017). The Impact of Organizational Justice on Employee Performance in Public Sector Organization of Pakistan. International Journal of Economics \& Management Sciences, 6(3).

Zhao, X., Lynch Jr., J. G., \& Chen, Q. (2010). Reconsidering Baron and Kenny: Myths and truths about mediation analysis. Journal of Consumer Research, 37(2), 197-206. 